\title{
The Mechanisms of Transition from Effectual to Causal thinking in Entrepreneurial Contingency
}

\author{
William $\operatorname{Lin}^{1}$ \\ ${ }^{1}$ Department of International Business, National Taiwan University, Taiwan, R. O. C \\ Correspondence: William Lin, Department of International Business National Taiwan University, 14F., No.563 \\ Sec. 4, Zhongxiao E. Rd. Sinyi Dist., Taipei City, Taiwan, R. O. C. E-mail:william.lin@wiskeycapital.com
}

Received: March 2, 2017

Accepted: April 20, $2017 \quad$ Online Published: April 27, 2017

doi:10.5539/ijbm.v12n5p51

URL: https://doi.org/10.5539/ijbm.v12n5p51

\begin{abstract}
Most entrepreneurial research has not addressed the phenomena of entrepreneurial teams adjusting their cognitive styles based on the different challenges they face during the new venture life cycle under startups, accelerators and incubators. Our objective in this article is to attempt to investigate the mechanism between effectuation and causation over the life cycle of ventures; and to explore the consequences of this transition and these mechanisms. Drawing on data from 64 in-depth interviews with 28 executive members, we recorded 172 key decisions chronologically and examined the pattern of decision-making processes. According to our observations and interviews, many companies remain at the survival stage for some time even when they know their breakeven point is reachable. We found that the remaining decision, the decision to remain below breakeven, is a signal of cognitive style transition from a dominantly effectual model of decision-making and action to a causation model. Our examination supported the mechanisms with effectuation principles and explored how the transitions between the two decision-making processes impact start-up teams. Our study not only extends effectuation research by examining the significant timing for transition timing, but also sheds light on entrepreneurial research by integrating and synthesizing transaction cost economics.
\end{abstract}

Keywords: effectuation, entrepreneurial team, accelerator and incubator, remaining decision

\section{Introduction}

The influence of decision-making in entrepreneurial contingency has long been an important issue of focus for researchers in effectuation theory and strategic management. Many have assumed that entrepreneurs engage in a rational goal-driven, causation cognitive style in order to search for and exploit opportunities (Fiet, 2002). Causation and effectuation are different decision-making models in their essences (Sarasvathy, 2001; Read \& Sarasvathy 2005). The former was developed along the theories of economics and strategy management for explaining how entrepreneurs use resources to guide their decision-making process through a particular effect (Lemos \&Andreassi, 2014). The latter was developed by Sarasvathy (2001) based on previous research of Knight (1921), Weick (1979), March (1982) and Mintzberg (1978, 1994), as an alternative approach for explaining the creation of artefacts in accordance with an entrepreneur's experience and the lack of resources of a firm. Although, Newbert and Tornikoski (2012) argued that the governance and content of the supporter network, along with network growth, are important in predicting organizational emergence, and the structure and content of the supporter network may inform the need for network growth. None of the effectuation literature has examined how entrepreneurs adjust their cognitive thinking logic within the business network. In order to fill this gap, we attempt to examine the possibility of effects on the centrality of the firm on its organizational structure, and this latter on the predominance of entrepreneur's both decision-making processes. Moreover, previous effectuation research has mainly focused on the cognitive style of individual founders. As the majority of new ventures are founded by teams after they decided to join an accelerator or incubators network environment, their cognition diversity of effectuation and causation in the new venture teams is a fruitful research avenue and as such, we have focused from the team level to the network mechanism level (which is the organization level in this research).

Our study contributes to entrepreneurial research in the following ways: (1) We extend Saravathy's proposition by showing the timing of transition between effectuation and causation during the new venture life cycle and essay this undeveloped topic a fruitful research avenue. (2) We shed light on new venture growth by illustrating 
how entrepreneurial teams need to adjust cognitive styles and decision behaviors when facing different challenges from different stages. (3) Our research also provides managerial implications by suggesting that cognitive approach is a significant factor to consider when entrepreneurs select their founding partners and funding approaches.

\section{Literature Review}

We attempt to explore the mechanism of consequence of transition from effectual to causal thinking in new venture growth. Then, we also review the literature on effectuation and enterprise growth models. In the end, we present how these streams of research jointly inform our research settings.

\subsection{Entrepreneurial Environment: Incubators and Accelerators}

With the changing of the global economy and new trend of the Internet and mobile-Internet boom, experienced entrepreneurs or spin-off companies are to sustain their existing advantages, create competitive equilibrium and maintain certain networks that remain persistent and resources when absolutely necessary in their pursuit of positioning and value propositions.

In terms of the similarities and differences in services, Bruneel et al. (2012) find that while all generations offered similar support services, entrepreneurial teams in the older generation of incubators made less use of the service portfolio. They suggest that this is a consequence of slack selection criteria and the absence of clearly defined exit policies among different incubators. Scillitoe and Chakrabarti (2010) highlight variations in counseling and networking interactions across incubators, and how these features impact the incubation process of new ventures.

Looking at the big picture, the literature reveals that while incubators and accelerators are widespread and appear to have a positive effect on innovation and entrepreneurship, there are gaps in our understanding of the intricate linkages between the characteristics of the two types of organizational networking and the performance they deliver via entrepreneurs' decision-making processes. However, none of the existing research has discussed whether, when or how these mechanisms affect the entrepreneurs' decision-making process over the new venture life cycle. Our work aims to fill in this gap by investigating the mechanism and consequence of transition in entrepreneurial contingency.

\subsection{Entrepreneurial Decision Model: Effectuation vs. Causation}

Entrepreneurs have cognitive approaches and mental preferences that influence their decision-making. Most entrepreneurship researchers have assumed that entrepreneurs engage in a rational goal-driven, causation cognitive approach to search for and exploit opportunities (Fiet, 2002). Causation is consistent with planned strategy approaches (Chandler et al., 2011). The planning and analysis required by such models assume conditions in which the distribution of outcomes in a group is predictable through calculation or statistical inference (Sarasvathy, 2001). In contrast, effectuation processes are consistent with emergent (Mintzberg, 1978) or non-predictive strategies (Wiltbank et al., 2006). Under conditions of uncertainty, unique circumstances make it impossible to draw statistical inferences. Sarasvathy (2001) has argued that entrepreneurs employ another cognitive approach, effectuation and causation, which reflect the extremes of cognitive approaches. Different authors (Dew \& Sarasvathy, 2002; Kupper \& Burkhart, 2009; Goel \&Kerri, 2006; Wiltbank,et al., 2009; Dew, et al., 2006) described the causation and Effectuation theoretical principles. The two main decision-making models, effectuation and causation, reflect the extremes of cognitive approaches.

Effectuation entrepreneurs create their new ventures with a given set of means in hand; they focus on affordable loss, leverage contingencies and strategic partners, and seek to control an unpredicted future (Sarasvathy, 2001). Causal entrepreneurs conduct comprehensive search or analysis to select the means by which they may achieve their pre-set goals at the highest return. They tend to focus on competitor analysis and attempt to predict an uncertain future in order to control the outcome. Saravathy (2005) has argued a model of the effectuation process. The effectuation process starts with an important self-awareness of who I am, what I know and whom I know. Therefore, Saravathy (2005) found that expert entrepreneurs have their business network structure other than novice entrepreneurs' people network. In other words, expert entrepreneurs start with three categories of means: their identity, their knowledge base, and their social network. The expert entrepreneurs try to gain primary customers and dedicated partners, who in turn create new means and new goals as resources and viewpoints are added to the mix. Thus, instead of having a specified goal and finding means to reach it, expert entrepreneurs use the new means and new goals to drive the creation of the venture in ways they hadn't expected.

Causation and Effectuation are different decision-making models in their essences (Sarasvathy, 2001; Read \& Sarasvathy 2005). There are still many unsolved puzzles in effectuation and causation processes to influence the 
entrepreneurs' decision-making processes. Read and Sarasvathy (2005) argued that effectual logic is emphasized in the earlier stages of venture life and the entrepreneurial teams should transit to a more causal logic at some status over the life cycle. Although, Liu (2015) argued that the breakeven point of a venture life cycle affects the transition of effectual and causal thinking, there is still not much research that focuses on what and how the status of venture life triggers the consequences of transition. Our research aims to fill the gap by investigating the consequence of transition of effectuation and causation decision-making processes over the entrepreneurial contingency in the organizational network (accelerators and incubators).

\subsection{Entrepreneurial Teams' Growth Model}

According to Greiner (1998), management practice cannot be maintained throughout the life span of an organization; neither company problems nor their solutions remain the same as the firm grows. In Greiner's view, firms grow in successive stages from birth to maturity and face a series of problems and crises such as leadership, autonomy, control, and coordination as they move on and grow. Krasniqi (2012) proposed that a founder's involvement in general management activities may be of decreasing importance or even detrimental as the transfer of decision-making power from owners to managers increases the firm's managerial capabilities. Much previous research has developed several different growth models from different perspectives, such as the corporate business growth model and small business growth model (Greiner, 1972; Churchill \& Lewis, 1983; Scott \& Bruce, 1987). As an entrepreneur firm it moves through five growth stages: (1) Existence; (2) Survival; (3) Success (disengagement and growth); (4) Take-off (delegation and cash); (5) Resource Maturity. Each stage is characterized by an index of size, diversity and complexity and described by five management factors: (a) management style, (b) organizational structure, (c) extent of formal systems, (d) major strategic goals and (e) the owner's involvement in the business (Churchill \& Lewis, 1983). Because the transition from one stage to the next requires change, it will be accompanied by some crisis or another. Crises tend to be disruptive and the problems of change can be minimized if managers are proactive rather than reactive (Scott \& Bruce, 1987). Therefore, as entrepreneurial firms move to the next stage, the key decision maker will adjust his or her thinking process and skill sets to adapt to the coming uncertainty from next stages. We believe, for the entrepreneurs, finding the key survival factors (KSF) is more important than maintaining key success factors (KSF). Therefore, we believe the remaining decision for an entrepreneur team, especially for key decision makers, involves a significant shift in demands thus giving us a good chance to explore the consequence of the transition from effectuation to a causation decision-making processes under different levels of uncertainty.

In our research, we followed Churchill and Lewis's five stage growth model (including substage assumption) and we used the breakeven point as the key exit index of the survival stage (Liu, 2015). Also, we employed Churchill and Lewis's key management factors (enterprise: financial resource, personnel resource, system resource and business resources; owner: owner's goals, owner's operational abilities, owner's managerial ability and owner's strategic abilities) to discover the adapting behavior under uncertainty of different stages and events.

\section{Methods}

We attempt to explore the insights underlying the transition from effectuation to causation and also its related influence over the entrepreneurial contingency. With the given limitation of understanding on the topics we would like to explore, we conducted a multiple case study of 10 entrepreneurial teams, working recursively between our multiple cases (Eisenhardt, 1989; Yin, 1994) and developed our propositions and process models.

\subsection{Samples and Data}

\subsubsection{Sample selection}

In order to find the suitable samples to fit our research topics, we set up several criteria to filter out improper cases: (a) young entrepreneurial teams, which were founded within the previous five years, (b) most of the key decision makers are novice entrepreneurs, (c) have moved from the survival stage to growth stage, and (d) the supporting organization (incubator and accelerators) do not belong to any university or government; they are individual business-oriented organizations. As we described previously, our goal is to explore the consequence of transition from effectual to causal decision-making processes in entrepreneurial contingency. We chose four teams from a Taiwanese incubator in Taipei, and six teams from China accelerators in Beijing and Hangzhou.

\subsubsection{Data Collection}

We collected data from the following five data sources in this research: (a) qualitative data from 64 in-depth interviews; (b) second interviews to clarify further questions in Taiwan; (c) email and phone calls for the China teams to clarify further questions; (d) archival data from company website, press releases, publications and incubator or accelerators; (e) on-site observations. 
For each company, we composed interview questions in three parts: (a) creating a written account of key decisions; (b) influence from incubators and accelerators; (c) discussing individual cognitive styles. We referred to a previous validation study (Chandler, DeTienne, McKelvie \& Mumford, 2011) and Sarasvathy's five effectuation principles to design interview questions of the third part. Our primary data source was semi-structured interviews with all 28 executive members from the entrepreneurial teams, 10 employees from each company, and 10 clients (including patients) who employed the service. We also collected background information from company websites, press releases and publications to record historical events of each company to design interview questions for the first part. Meanwhile, we also interviewed the founders and managers of the incubators and accelerators regarding our information from entrepreneurial teams and our target company studying.

We limited each interview to a maximum of 90 minutes to avoid constraints of human attention. Each interview was voice recorded and transcribed. Table 1 presents a summary of the background and data of target companies.

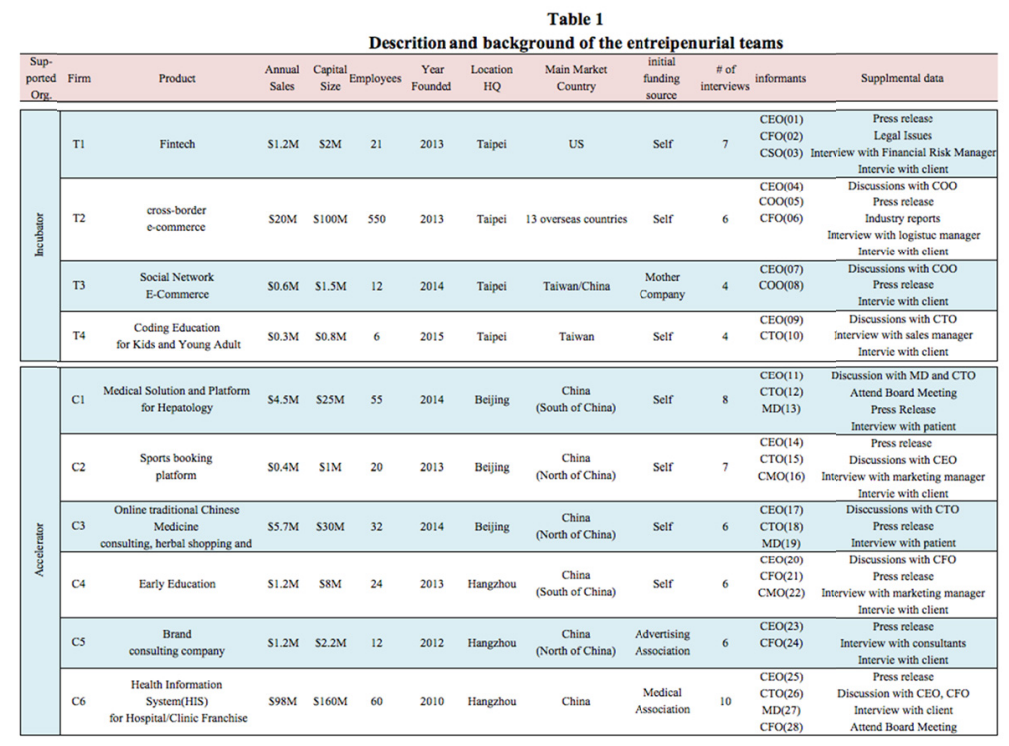

As informant bias is an important concern, we address bias in several ways: (1) we recorded each executive member and asked his or her personal perspective on the same written account of events and cross checked their responses; (2) we interviewed one key employee from each company for their observation of their executive teams to acquire outsider information; (3) we interviewed one client for each company in order to gain more information on market site and service level; (4) we supplemented our interview data with archival information; (5) we analyzed interview data separately with research assistants in different cities and cross-checked with incubators and accelerators on our observations and also obtained more information from different points of view in their working environment. We believe these steps improved memory accuracy, yielding a more complete and accurate picture of all these interactions and decisions. Furthermore, multiple sources of information triangulated our data and helped reduce information bias.

\section{Analysis}

Before we started to edit the written account of decisions in each case, we began our data analysis with each individual case and then conducted cross-case comparative analysis. We supplemented chronicles with archival data by synthesizing individual interviews with each executive, employee and clients in order to present when and how their key decisions occurred (please see Table 2 for Case T1 summary as an example). 


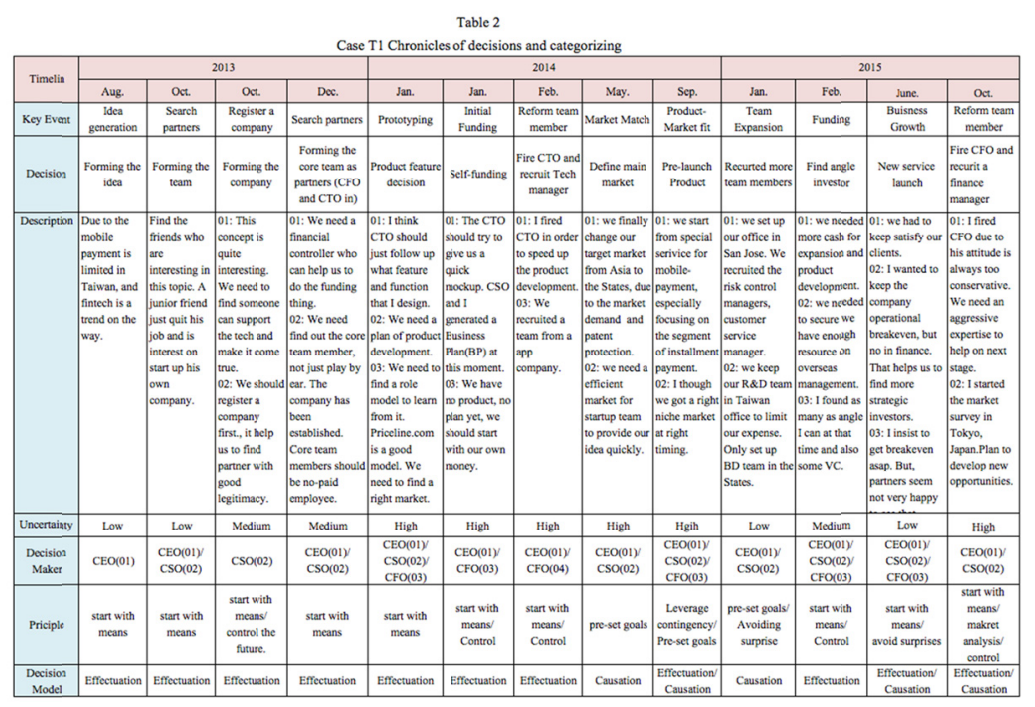

In the next step, we codified the decision model of each executive member with Sarasvathy's five principles and generated a team cognitive style diversity table. (please see Table 3 for the team of case T1 as example).

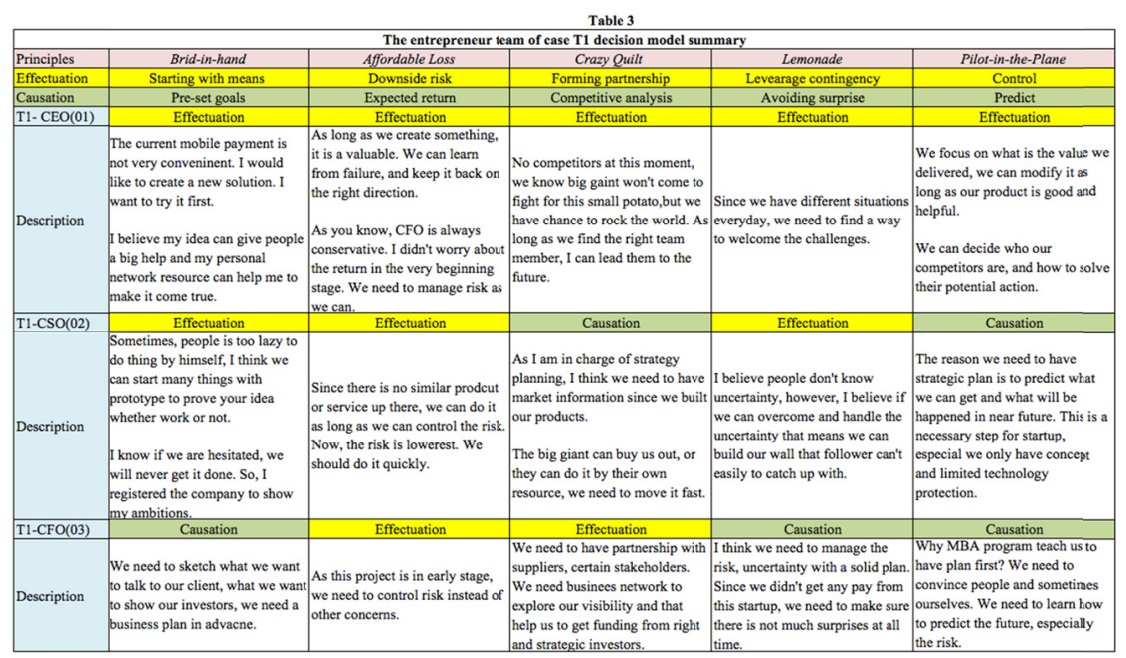

Based on these two analyses, we focused each case analysis on developing mechanisms and explored the consequence of the transition between effectuation and causation cognition style. In the next section, we demonstrated how we analyzed case $\mathrm{T} 1$ as example and summarized our key finding later.

\subsection{Case T1 Analysis}

Two MBA friends started with the idea of establishing a company to develop a mobile payment app in March 2013. As fintech (financial technology) is a new trend of application on mobile Internet service, the founder started with the draft idea and he was looking for a junior partner to support his idea. They discussed and shared the same value: Enabling anyone to buy or sell anything in installments. This passion drove the founder (CEO) to grab the resource to help him make the dream come true. The $\mathrm{CSO}(02)$ described the motivation when he heard this innovative idea from CEO (01):

I thought CEO (01) sketched a correct direction and that I could help him to make this a feasible solution according to my personal network and communication skill. I introduced him to a lot of potential partners and investors, we didn't worry that our team lacked technical support; I believed we could convince the high talent hackers to code it up. I know many of them.

CEO (01) recalled:

I believe my idea could give people a big help and my personal network resource could help me to make it come 
true. Just grab the people who are interested in it and make a prototype. We focused on what would be the value we delivered, we could modify it as long as our product was good and helpful.

CSO (02) explained the next action he made:

I thought we needed to start a company first, a real company would help us to persuade people to join us and we would get the legitimacy of being realistic.

From interview data, supplemented with archival documentation, we recorded these effectual decisions with the principle of start with means and control the future.

Company T1 was established by CSO (02) before they found the core team members. They then invited CFO (03) and CTO as cofounders from their people networks and joined the biggest incubator in Taipei through CSO (02)'s engagement. However, the core team members had some arguments on the specs and features of the product. We coded this decision as effectual. (start with means).

The conversation between CEO (01) and CSO (02) shows what they thought about the internal arguments at that moment. The CEO (01) explained:

As long as we created something, it would be valuable. We could learn from failure, and keep it back on the right direction.

The CSO (02) concurred:

Since there was no similar product or service up there, we could do it as long as we could control the risk. At that moment, the risk was the lowest. We should do it quickly.

The CFO (03) noted:

We needed to sketch what we wanted to say to our client, what we wanted to show our investors, we needed a solid business plan in advance. We needed a plan of milestones!

In early 2014, Company T1 had no real product. Six months had already passed since they started this project. CEO (01) decided to fire the CTO and recruited a technical manager instead. Core team members were reduced to three people as CEO (01), CSO (02) and CFO (03). CEO (01) explained that:

Since we had different situations everyday, we needed to find a way to welcome the challenges. We could find a proper technical support and speed up the process.

CFO (03) responded:

We finally got our prototype of the product in beta version. We still needed to manage the risk, uncertainty with a solid plan. Since we didn't get any pay from this startup, we needed to make sure there were not many surprises at all times.

CSO (01) described the arguments and unstable atmosphere and turned the focus on the market demand site:

As I was in charge of strategy planning, I thought we needed to have market information since we built our products. I thought we got a right niche market at the right timing.

In the fourth quarter of 2014, Company T1 had over 10,000 clients to register for their service and the sales revenue had increased beyond the forecast. CEO (01) decided to set up an office in San Jose, CA, and adjust a market segment into the marketplace service. CEO (01) noted:

We could decide who our competitors would be, and how to solve their potential actions to attack us. We moved to the US market and started from San Jose. We needed to recruit a financial risk manager and customer service manager that would help us to look mature to get interest from good investors in Silicon Valley. We got fruitful support from the incubator that helped me to get more confidence in the face of contingencies.

CSO (02) concurred:

We kept our $R \& D$ team in the Taiwan office to limit our expenses. Only set up a business development team in the States. Needed to move to the next geographical market later. We needed next funding.

$\mathrm{CFO}(03)$ recalled:

I knew the financial breakeven was on the way. I wanted to get more funding. More cash could help us to avoid surprises even as we reached breakeven.

At the survival stage, Company T1 made some decisions with effectual logic. They combined the effectuation and causation approaches to make the critical decision regarding forming of the core team and the funding plan. 
CEO (01) mainly focused on coordinating all kinds of resource needed and making sure the product and service were ready. Meanwhile, CSO (02) was dedicated to marketing contingency and exploring the network of the macroculture in the mobile Internet industry. CFO (03) was concerned more with financial support and safeguarding the value they had developed and exploited. We interviewed a client who employed the service from Company T1. The client's comment:

This is a really innovative service. There is no alternative solution. Obviously, I love to use their service. However, I think they might have some problems: if big banks saw this opportunity, Company T1 might get in trouble.

In early 2015, Company T1 raised another funding plan right before their breakeven point. CFO (03) was fired after the funding was completed. CSO (02) noted:

We knew we would reach the breakeven in the first quarter of 2015. However, we wanted to keep our financial status under the breakeven point. That helped us to prepare more resources, especially financial support, to move on to a new product launch. We didn't want the big giants to see what we are doing now. To keep fundraising was a good signal to outside that we were still suffering.

Since Company T1 had launched their new service and extended their territory to marketplace, CEO (01) explained:

We needed different strategic investors and partners in different category. The plan to do the fundraising before the breakeven gave us much flexibility in developing a new product, new market segment and build entry barriers. We could foresee the coming battles from big competitors and adapt to it.

We tracked the decision-making process of the entrepreneurial team of Company $\mathrm{T} 1$ on the basis of chronicles of decisions and found that not only was the breakeven an important event, but also that the fund-raising plan just before the breakeven point in the previous quarter was a signal that they were ready for their next action before the predictable economic breakeven point in order to maintain flexibility for survival. Company T1 experienced eight effectual decision-making processes and three causal decision-making processes before the economic breakeven point. Meanwhile they experienced two effectual, four causal and two hybrid decision-making processes after the economic breakeven point. As a result, we found that the decision-making processes from effectuation to causation on the observations of interviews among key executive members.

Moreover, we continued each individual case analysis, progress through the steps of qualitative research and summarized our major results in Table 4. Then, we conducted cross-case comparative analysis to develop our propositions and findings in the next section.

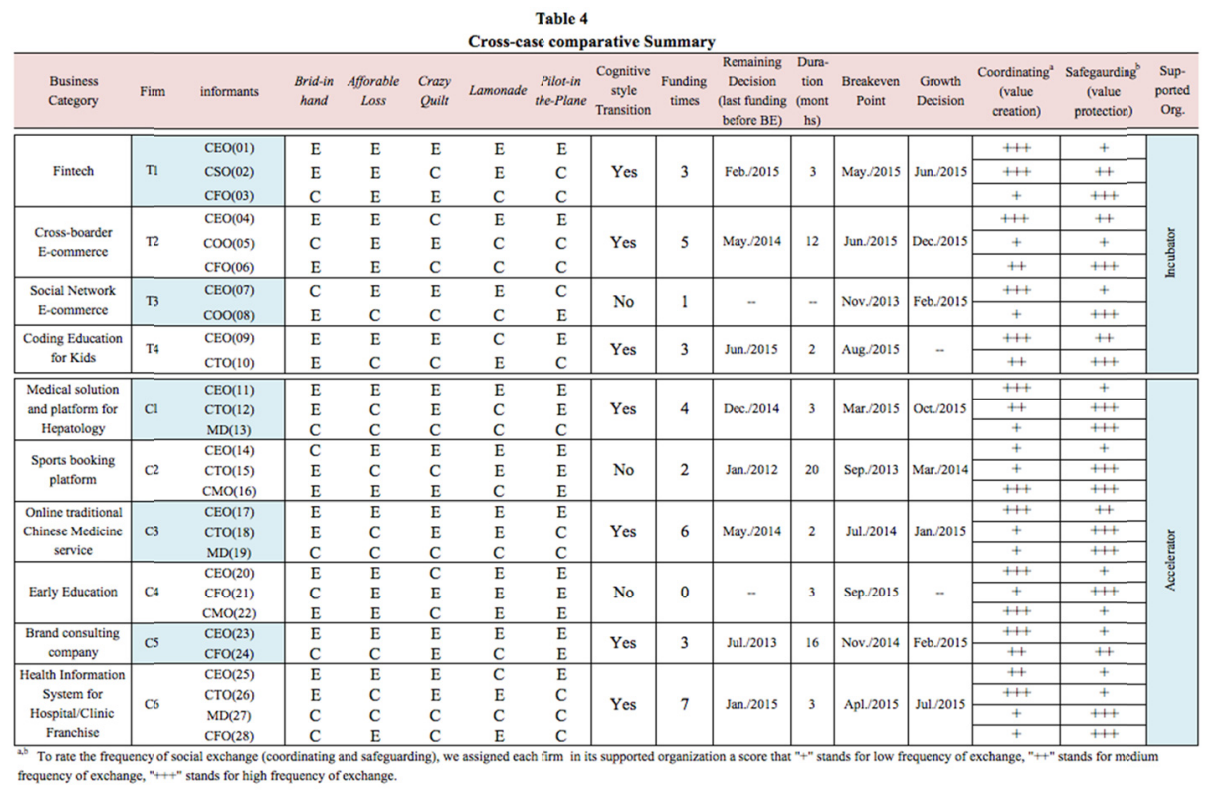

\section{Findings}

\subsection{Supporting Organization (Incubators and Accelerators)}

The supporting organization, such as incubators and accelerators, provide a cluster environment to help 
aggressive entrepreneurs get their necessary resource efficiently. Barbero et al. (2014) found that some types of incubators are more prolific in generating product and process innovation than others. Using data on Helsinki-based incubators, Abetti (2004) found a positive relationship between incubators and economic growth. Clausen and Rasmussen (2011) found that publicly supported incubators were able to transfer knowledge and most of these activities would not have taken place without incubators.

In 2014, CEO(09) decided to join an incubator to get more resource and networks in order to expand their business on scale considerations. In 2013, CEO(11) and CTO(12) decided to move into accelerators to get more exposure on market development. In 2012, CEO(25) and CTO(26) were introduced by a medical association to an accelerator in Hangzhou. They got a lot of promotion to catch more global investors' attention. Although a few entrepreneurial teams might not experience influence from revenue expansion, user engagement or business development, there were still many network activities through the supporting organization on resource considerations. $\mathrm{CEO}(11)$ from a Company $\mathrm{C} 1$ explained:

I think all new venture firms need to find a proper incubator or accelerator to help them get stable quickly and reduce the time on searching for talents and strategic investors.

$\mathrm{CTO}(26)$ from Company $\mathrm{C} 6$ describes the decision in transition after he moved into an accelerators:

I could never imagine that I almost could get any kind of technical talents in the network of the accelerator. Of course, you could verify a personal reputation easily before you hired somebody. Fast, good talents and the right direction were the major impacts that I got from the accelerator. It helped me to handle the potential risk on the security issues of patients.

Newbert and Tornikoski (2012) argued that with whom and with how many people an entrepreneur has ties is far less important than how embedded those relationships are and what he/she is able to access from them. Furthermore, this is particularly important given that enlarging a supporter network is a process that requires the investment of significant time, money and other resources, which entrepreneurs generally lack.

We adopted the mechanism from Jones et al. (1997) to explain how incubators and accelerators can help entrepreneurs get their particular resources and solve problems.

As $\mathrm{CEO}(17)$ of Company $\mathrm{C} 3$ recalled:

The accelerator helps us to handle different situations, such as legal issues and regulation requirements from government and clients. We can ask other entrepreneurs or mangers in other companies that are supported by accelerators.

CTO(12) of Company $\mathrm{C} 1$ concurred:

I am not that familiar with medical regulation, $M D(19)$ of Company $C 3$ helped me to get a better understanding of how to avoid the risk from pharmacenticals when I couldn't find a solution from our medical director, $M D(13)$.

Based on our observation and investigation, the efficient exchange can reduce the communication cost. This helps in value creation for a team with lower costs and value protection with managing customized exchange. The efficient exchange can enhance the awareness and ability to cause comprehensive thinking approach. We offer the following:

Proposition 1: Multiple social mechanisms in supporting organizations (incubators and accelerators) of restricted access, macroculture, collective sanction and reputation interact to decrease coordination costs, enhance safeguarding and encourage adapting frequency in entrepreneurial contingency.

\subsection{Cognitive Diversity and Remaining Decision}

The entrepreneurial contingency brings various demands through the different growth stages of the new venture firm life cycle. Entrepreneurs face a high level of uncertainty and utilize effectual logic to handle most changes in the near future. When new venture firms pass the critical point and survive, business conditions bring another challenges for the next stage. Entrepreneurial firms move from the existence stage to the survival stage, they need to obtain customers and deliver their product and service. They aim to the next stage of survival by shifting from mere existence to a relationship between revenues and expenses. When they move from the survival stage to the success stage, they may grow in size and profitability and move on to the next stage. Many companies remain at the survival stage for some time, earning marginal returns on invested time and capital (Churchill \& Lewis, 1983). Not many new ventures rely on effectual logic to make growth decisions and they might fail to detect emerging competition or to comprehensively analyze market complexity (Liu, 2015). Entrepreneurial teams begin to transit cognitive styles from effectuation logic to causation logic when they reach the breakeven point. They thus decide to rush into new businesses, leading to overtrading traps and sometimes ending in 
failure.

Company T3, C4 and C5 raised their funding by three months even more than 12 months before their breakeven point. Company T3 is a spin-off company from its mother company. So, we assume that Company T3 has strong financial support as they only raised one time funding in the very beginning. Company $\mathrm{C} 4$ has sufficient initial capital and it provides early education service to handicapped children. Company $\mathrm{C} 5$ raised its funding before breakeven point over one year ago. As $\mathrm{CFO}(24)$ explained:

Due to our feature of our industry, we provide brainpower, creativity and communication ability as our service help our clients to create value of their own branding image. We only need to maintain the downside risk, focusing on expense control and keeping our designer happy.

This company utilized effectual logic from day one until we had interviewed them twice. They kept the dominant style of thinking to handle and solve most issues and challenges.

Read and Sarasvathy (2005) proposed that at some point in the life cycle of startup firms, founders would have to move from a predominantly effectual model of thinking and action to a causal model because of fundamental business context changes. As MD(27) of Company C6 reported in his email:

I was surprised that before we knew when we could reach the financial breakeven point, I felt the top managers changed for some reason. They discussed more issues on the analysis of competition and a detailed plan for forecasting. They planned to do fundraising right before a quarter of reaching breakeven on forecasting.

$\mathrm{CTO}(10)$ had the similar observation before the breakeven point of Company T4.He described:

Our CEO(09) started to re-sketch the goal as solidly as possible after we knew that we could reach the breakeven next quarter. It seemed she was preparing something and she just kept it in her mind only. I was happy to see this happen. That meant instead of worrying about the risk, I can focus on my product development plans.

The entrepreneurial teams started to transition from effectual decision-making to causal decision-making when they reached the breakeven. Moreover, before the transition started, we found that some decision-makers started to implement fundraising plans or grab more resources. It seemed that when the decision maker became aware of the signal of breakeven potential, their motivation of "doing some preparation" would be triggered. This helped them to start thinking more about complexity issues. As CEO(14) explained:

When I realized the breakeven was on the way, it enhanced my confidence on developing more related business. As the possibility increased, I tried to ask my medical director $M D(19)$ whether we could dream to adopt our service to other pharmacies. I started to plan a detailed funding story and looking for other strategic investors to help me expand my business.

We traced the pattern of 172 key decisions from these new venture firms (please see Table 5 for a summary). Before reaching the breakeven point, Company T1, T4, C1, C3 and C6 had revealed signals to propose a funding plan. We coded this signal as "Causation-like", such as developing a fundraising plan three months before breakeven point. However, as we reported previously, Company T3, C4 and C5 were still in effectuation logic until we finished this proposal due to their special backgrounds. Table 5 shows the key decision patterns, which are related to the transition from effectuation to causation.

\begin{tabular}{|c|c|c|c|c|c|c|c|c|c|c|}
\hline \multicolumn{11}{|c|}{$\begin{array}{l}\text { Table 5 } \\
\text { Key decision related to tansition from effectuation to causation }\end{array}$} \\
\hline \multirow{2}{*}{$\begin{array}{l}\text { Loca- } \\
\text { tion }\end{array}$} & Consquence & $\begin{array}{c}\text { Remaining Decision } \\
\text { (last funding before } \mathrm{BE} \text { in }\end{array}$ & \multicolumn{3}{|c|}{ Before breakeven } & \multicolumn{3}{|c|}{ After breakeven } & \multirow{2}{*}{ Transition } & \multirow{2}{*}{$\begin{array}{l}\text { Suvival } \\
\text { decision } \\
\text { related to } \\
\text { transition }\end{array}$} \\
\hline & Decsion Model & Causation potential & Effectuation & Hybrid & Causation & Effectuation & Hybrid & Causation & & \\
\hline \multirow{4}{*}{ 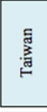 } & Case T1 & Causation-like & 8 & & 3 & 2 & 2 & 4 & Yes & positive \\
\hline & \begin{tabular}{|l|} 
Case T2 \\
\end{tabular} & No signal & 5 & 3 & 2 & 3 & 3 & 3 & Yes & non-positive \\
\hline & Case T3 & No signal & 8 & 2 & & 4 & 2 & 1 & No & - \\
\hline & Case T4 & Causation-like & 6 & 2 & 2 & 1 & 3 & 4 & Yes & positive \\
\hline \multirow{7}{*}{ है } & Case C1 & Causation-like & 7 & & & 2 & 1 & 2 & Yes & positive \\
\hline & Case C2 & No signal & 9 & & & 3 & 1 & 1 & No & - \\
\hline & Case C3 & Causation-like & 6 & 2 & 1 & 2 & 3 & 3 & Yes & positive \\
\hline & Case C4 & No signal & 8 & 1 & & 4 & 2 & 1 & No & - \\
\hline & Case C5 & No signal & 7 & 2 & & 2 & 1 & 3 & Yes & non-positive \\
\hline & Case C6 & Causation-like & 4 & 3 & 2 & 1 & 1 & 4 & Yes & positive \\
\hline & Subtotal & - & 68 & 15 & 10 & 24 & 19 & 26 & & \\
\hline
\end{tabular}

We calculated the duration between last funding time and the breakeven point from our interview; it shows a positive relationship with the transition of decision-making from effectuation to causation. This phenomenon has not been shown in previous literature reviews and articles. On the basis of our analysis and observations, we propose that entrepreneurial cognitive style diversity will reveal certain conservative action before the breakeven point. 
Proposition 2: Diversity in cognitive approaches (effectuation and causation) in new venture teams will be revealed before breakeven point by certain signal ("survival decision"), such as a comprehensive fundraising plan.

\section{Discussion}

In previous entrepreneurship research, most researchers have argued that entrepreneurs make their own decisions in business contingency through a rational goal-driven process. Read and Sarasvathy (2005) argued that effectual logic is emphasized in the earlier stages of venture life and the entrepreneurial teams transit to a more causal logic at some point over the life cycle. We extended from effectuation research by proposing an exchange mechanism of consequence of cognitive style transition. Our research investigates the mechanisms during the timing of transition between effectuation and causation over the life cycle of business launched by entrepreneurial teams; and explored the governance structure alongside effectuation and causation.

Dutta and Thornhill (2008) examined the relationship between growth intention, cognitive styles (holistic vs. analytic) and perceived competitive conditions in a sample of 30 entrepreneurs. They found that entrepreneurial cognitive style moderates the relationship between perceptions of the competitive environment and growth intentions. Unlike Dutta and Thornhill's argument, we propose that entrepreneurial teams make survival decisions before their growth decision. There is a significant signal of action when they foresee the coming economic breakeven point. We define this signal as the "remaining decision". Furthermore, when a new venture team tries to exit from the existence stage to the survival stage, they try different ways to obtain customers. When they shift to the survival stage and plan to move to the next stage, they might activate their remaining decision instead of jumping into a growth decision to obtain a safeguarding position. According to our observations and interviews, many companies remain at the survival stage for some time even when they know their breakeven point is reachable. They do so to earn marginal returns on invested time and capital or to keep more resources and bargaining power for the next using an analytic logic as causal decision-making process. In order to cause comprehensive consideration, the remaining decision supports causation logic when the entrepreneurial teams learn from their supporting organization by coordinating or safeguarding exchange. Therefore, the efficient supporting network will reduce the novice entrepreneur's coordination costs and enhance the safeguarding of customized exchanges in business contingency. We demonstrate a simple process model in the next section and encourage further investigation to extend it.

As noted above, new entrepreneurial teams will demonstrate cognitive style diversity from effectuation to causation after reaching the breakeven point. Figure 1 shows how the mechanism chosen will generate the total enforcement value when a new venture firm moves from the survival stage to the success stage. Under entrepreneurial contingency, the consequences of transition from effectuation to causation are arrayed on the $\mathrm{x}$-axis. The $\mathrm{y}$-axis shows the level of enforcement value, the value created by coordinating and value protection by safeguarding and their sum, total enforcement value.

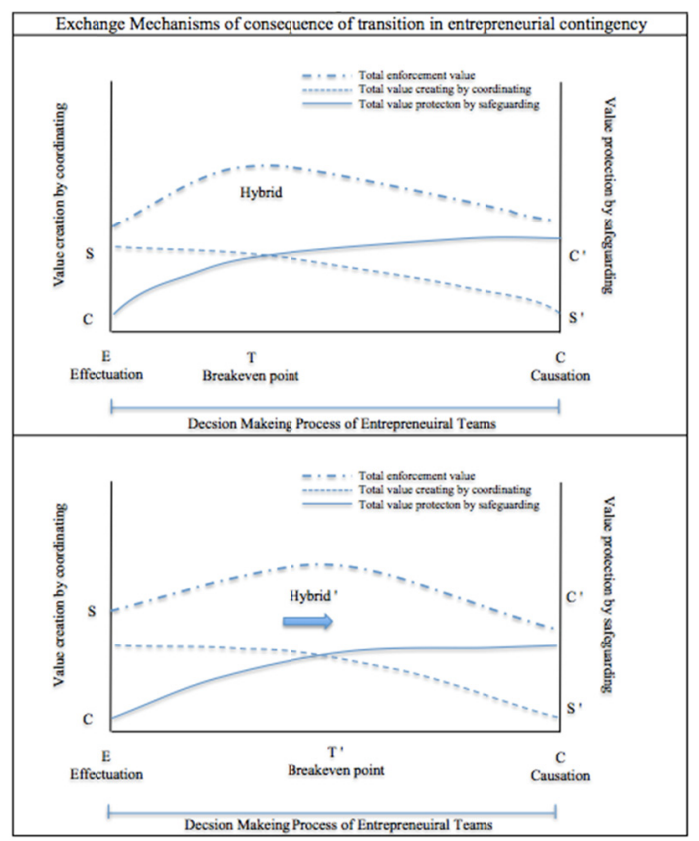


The mechanism demonstrates the relationship of consequence of transition from effectual to causal decision-making process in entrepreneurial contingency when new venture firms in efficient environment as shown in Figure 1.

The level of total value protection by safeguarding for a new venture firm is given by line CC'. Consistent with the argument made above, $\mathrm{CC}^{\prime}$ rises as exchange incentives are loosened because this loosening improves incentives by causation logic. Read and Sarasvathy (2005) argued that major research in entrepreneurship sets out a causal process that begins with the identification, recognition or discovery of an opportunity, followed by a series of tasks that include (a) developing a business plan based on (b) extensive market research and (c) detailed competitive analyses, followed by (d) the acquisition of resources and stakeholders for implementing the plan, and then (e) adapting to the environment as it changes over time with a view to (f) creating and sustaining a competitive advantage. SS', the total level of value creation by coordinating, reduces as conservative rewards are increasingly based on the challenge in entrepreneurial contingency, since the payoff to spend paid time to indulge in other pursuits increases with the proportion of breakeven on a time-basis. Point $T$, at the breakeven point, corresponds to a hybrid of coordinating encouragement and safeguarding constraints that is positive related towards output incentives. The upper graph shows how the cognitive style of an entrepreneurial team moves from an effectuation to a causation decision-making process by coordinating and safeguarding exchange on adapting the business contingency. The total enforcement value encourages the entrepreneurial team to reach the economic breakeven point. The lower graph shows the entrepreneurial team adopts more causation logic by manipulating the later breakeven point (Point T') in order to adapt more resources on handling certain business contingencies. We defined this signal before to breakeven point as the remaining decision. Figure 1 shows that the exchange mechanism helps entrepreneurial teams to understand how and when the cognitive style transition from effectual to causal decision-making process under business contingency. Furthermore, one assumption of the graph is that behavior and output measurement are substitutes only if there is only one decision-maker in the entrepreneurial team. In other words, it is not efficient to both increase coordinating encouragement and safeguarding constraints at the same time.

Finally, we would like to discuss Company T2. Company T2 had a different decision-making process than the other cases and thus we can observe some signals after they knew the economic breakeven was reachable. We didn't observe any signal (causation-like or remaining decision) before their cognitive style of transition. Company T2 combined both effectual and causal decision-making processes since forming the company. Read and Sarasvathy (2005) proposed that sufficient resources encourage the new entrepreneur's causation logic. Company T2 had available resources from a strategically powerful partner. This case also gives previous researchers strong support to their propositions.

\section{Conclusions}

In this article, we provide several contributions to a general understanding of the effectuation principle. We furnish a simple, integrated framework for understanding not only the cognitive style transition from effectuation to causation with the growth of new venture, but also the mechanisms of consequence of transition under business contingency. We extend effectuation theory from a qualitative research method of entrepreneurial teams' behavior.

Through our case study, we also raise significant questions in the fields of effectuation, cognitive diversity, the influence from supporting organization and new venture survival decision. We believe we have contributed to both effectuation and entrepreneurial team research in several ways.

First, based on our observation and investigation, we found the efficient exchange can enhance the awareness and ability to cause a comprehensive thinking approach. Second, on the basis of our analysis and observations, we propose that entrepreneurial cognitive style diversity will reveal a certain conservative action, the remaining decision, before the breakeven point. Finally, we provide a mechanism of consequence of transition in entrepreneurial contingency.

The remaining decision is a strategy of delay of gratification (Mischel, 1989) in order to get ready for the next challenge with consistent team cognition. The other managerial implication is that the communication gap between entrepreneurs and investors also can be applied by the mechanism that we proposed in this article. With the map of cognitive diversity, it is easy to imagine how entrepreneurs share little of their status with investors about the decision-making processes of the entrepreneur team. Also, we encourage entrepreneurs to gain more understanding during the partner selection period, since different characteristics cause different mechanisms of the decision-making model. 


\section{References}

Barbero, J. L., Casillas, J. C., Wright, M., \& Garcia, A. R. (2014). Do different types of incubators produce different types of innovations? The Journal of Technology Transfer, 39(2), 151-168. https://doi.org/10.1007/s10961-013-9308-9

Bruneel, J., Ratinho, T., Clarysse, B., \& Groen, A. (2012). The Evolution of Business Incubators: Comparing demand and supply of business incubation services across different incubator generations. Technovation, 32(2), 110-121. http://dx.doi.org/10.1016/j.technovation.2011.11.003

Chandler, G. N., DeTIENNE, D. R., McKelvie, A., \& Mumford, T. V. (2011). Causation and effectuation processes: A validation study. Journal of Business Venturing, 26(3), 375-390. http://dx.doi.org/10.1016/j.jbusvent.2009.10.006

Churchil, N. C., \& Lewis, V. L. (1983). The Five Stages of Small Business Growth. Havard Business School Publishing Computer Security Institute (2004).

Clausen, T., \& Rasmussen, E. (2011). Open innovation policy through intermediaries: the industry incubator programme in Norway. Technology Analysis \& Strategic Management, 23(1), $75-85$. http://dx.doi.org/10.1080/09537325.2011.537109

Dutta, D. K., \& Thornhill, S. (2008). The evolution of growth intentions: Toward a cognition-based model. Journal of Business Venturing, 23(3), 307-332. http://dx.doi.org/10.1016/j.jbusvent.2007.02.003

Eisenhardt, K. M. (1989). Building theories from case study research. Academy of Management Review, 14(4), 532-550. https://doi.org/10.5465/AMR.1989.4308385

Fiet, J. O. (2002). The Systematic Search for Entrepreneurial Discoveries. Westport, CT: Quorum.

Ghosal, V., \& Ye, Y. (2015). Uncertainty and the employment dynamics of small and large businesses. Small Business Economics, 44(3), 529-558. https://doi.org/10.1007/s11187-014-9614-0

Greiner, L. E. (1998). Evolution and revolution as organizations grow. Harvard Business Review, 55-66.

Jones, C., Hesterly, W. S., \& Borgatti, S. P. (1997). A general theory of network governance: Exchange conditions and social mechanisms. Academy of Management Review, 22(4), 911-945. https://doi.org/10.5465/AMR.1997.9711022109

Knight, F. H. (1921). Risk, uncertainty and profit. New York: Hart, Schaffner and Marx.

Krasniqi, B. A. (2012). Building an expanded small firm growth model in a transitional economy: Evidence on fast growing firms. Journal of East-West Business, 18(3), 231-273. http://dx.doi.org/10.1080/10669868.2012.728903

Lemos, A. Q., \& Andreassi, T. (2015). Effectuation and causation: Propositions about decision making process in business network environments. Revista de Negócios, 20(1), 29-43. http://dx.doi.org/10.7867/1980-4431.2015v20n1p29-43

Lewis, D. A., Harper-Anderson, E., \& Molnar, L. A. (2011). Incubating success. incubation best practices that lead to successful new ventures. Ann Arbor: Institute for Research on Labor, Employment, and Development, 1-144.

Liao, J., \& Welsch, H. (2005). Roles of social capital in venture creation: Key dimensions and research implications. Journal of Small Business Management, 43(4), 345-362. https://doi.org/10.1111/j.1540-627X.2005.00141.x

Liu, Y. T. (2015). Timing and Consequence of Transition from Effectual to Causal Thinking in New Venture Growth. In Academy of Management Proceedings (Vol. 2015, No. 1, p. 18401). Academy of Management. doi:10.5465/AMBPP.2015.18401abstract

March, J. (1982). The technology of foolishness. In J.G. March and J.P. Olsen (Ed.), Ambiguity and Choice in Organizations. Universitets forlaget: Bergen. https://doi.org/10.1016/0361-3682(87)90004-3

Milanov, H., \& Fernhaber, S. A. (2009). The impact of early imprinting on the evolution of new venture networks. Journal of Business Venturing, 24(1), 46-61. http://dx.doi.org/10.1016/j.jbusvent.2007.11.001

Mintzberg, H. (1978). Patterns in strategy formation. Management science, 24(9), 934-948. http://dx.doi.org/10.1287/mnsc.24.9.934

Mischel, W., Shoda, Y., \& Rodriguez, M. I. (1989). Delay of gratification in children. Science, 244(4907), 
933-938.

Newbert, S. L., \& Tornikoski, E. T. (2012). Supporter networks and network growth: A contingency model of organizational emergence. Small Business Economics, $141-159$. https://doi.org/10.1007/s11187-010-9300-9

Scillitoe, J. L., \& Chakrabarti, A. K. (2010). The role of incubator interactions in assisting new ventures. Technovation, 30(3), 155-167. http://dx.doi.org/10.1016/j.technovation.2009.12.002

Scott, M., \& Bruce, R. (1987). Five stages of growth in small business. Long Range Planning, $20(3), 45-52$. https://doi.org/10.1016/0024-6301(87)90071-9

Weick, K. E. (1979). The social psychology of organizing. Reading, MA: Addison-Weley.

Wiltbank, R., Dew, N., Read, S., \& Sarasvathy, S. D. (2006). What to do next? The case for non - predictive strategy. Strategic Management Journal, 27(10), 981-998. https://doi.org/10.1002/smj.555

Yin, R. (1994). Case study research: Design and methods. Beverly Hills.

\section{Copyrights}

Copyright for this article is retained by the author(s), with first publication rights granted to the journal.

This is an open-access article distributed under the terms and conditions of the Creative Commons Attribution license (http://creativecommons.org/licenses/by/4.0/). 